\title{
Development of a one-step multiplex qRT-PCR assay for the detection of African swine fever virus, classical swine fever virus and atypical porcine pestivirus
}

Huixin Liu ${ }^{1+}$, Kaichuang Shi ${ }^{1,2^{* \dagger}}$, Jing Zhao ${ }^{1}$, Yanwen Yin ${ }^{2}$, Yating Chen ${ }^{1}$, Hongbin $\mathrm{Si}^{{ }^{*}}$, Sujie $\mathrm{Qu}^{2}$, Feng Long ${ }^{2}$ and Wenjun Lu ${ }^{2}$

\begin{abstract}
Background: African swine fever virus (ASFV), classical swine fever virus (CSFV) and atypical porcine pestivirus (APPV) have caused great economic losses to the swine industry in China. Since coinfections of ASFV, CSFV and APPV occur in certain pig herds, it is necessary to accurately and differentially detect these pathogens in field-collected samples. In this study, a one-step multiplex real-time quantitative reverse transcription-polymerase chain reaction (multiplex qRT-PCR) was developed for the simultaneous and differential detection of ASFV, CSFV and APPV.

Results: The one-step multiplex qRT-PCR presented here was able to simultaneously detect ASFV, CSFV and APPV but could not amplify other viruses, including porcine circovirus type 2 (PCV2), pseudorabies virus (PRV), porcine reproductive and respiratory syndrome virus (PRRSV), foot-and-mouth disease virus (FMDV), porcine parvovirus (PPV), porcine epidemic diarrhoea virus (PEDV), transmissible gastroenteritis virus (TGEV), porcine rotavirus (PRoV), porcine deltacoronavirus (PDCoV), border disease virus (BDV), bovine viral diarrhoea virus type 1 (BVDV-1), BVDV-2, etc. The limit of detection (LOD) of the assay was $2.52 \times 10^{1}$ copies/ $\mu \mathrm{L}$ for ASFV, CSFV and APPV. A repeatability test using standard recombinant plasmids showed that the intra- and interassay coefficients of variation (CVs) were less than $2 \%$. An assay of 509 clinical samples collected in Guangxi Province, southern China, from October 2018 to December 2020 showed that the positive rates of ASFV, CSFV and APPV were 45.58, 12.57 and 3.54\%, respectively, while the coinfection rates of ASFV and CSFV, ASFV and APPV, CSFV and APPV were 4.91, 1.38, 0.98\%, respectively. Phylogenetic analysis based on the nucleotide sequences of the partial ASFV p72 gene showed that all ASFV strains from Guangxi Province belonged to genotypes I and II.
\end{abstract}

Conclusion: A one-step multiplex qRT-PCR with high specificity, sensitivity and repeatability was successfully developed for the simultaneous and differential detection of ASFV, CSFV and APPV.

*Correspondence: shikaichuang@126.com; shb2009@gxu.edu.cn

†Huixin Liu and Kaichuang Shi contributed equally to this work.

${ }^{1}$ College of Animal Science and Technology, Guangxi University, Nanning 530005, China

${ }^{2}$ Guangxi Center for Animal Disease Control and Prevention,

Nanning 530001, China

\section{Background}

African swine fever virus (ASFV) is an enveloped double-stranded DNA virus and the only member of the genus Asfivirus in the family Asfarviridae [1]. This virus causes African swine fever (ASF), a notifiable disease to the World Organization for Animal Health (OIE) characterized by high fever, extensive haemorrhage, pulmonary oedema and intensive lymphoid tissue necrosis, and 
it presents high morbidity and mortality [2]. ASF was first identified in Kenya in the 1920s, Europe in 1957, the Caucasus region and southern Russia in 2007 [3, 4], and China in August 2018 [5], where it rapidly spread to most provinces in China within a short time and adversely affected the swine industry [6]. Furthermore, ASF has been reported in other Asian countries, such as Mongolia, Korea, Vietnam, Laos, Cambodia, the Philippines, and Indonesia, since the end of 2018 [7]. ASF was recently reported again in the Dominican Republic in July 2021 (OIE-WAHIS, https://wahis.oie.int/\#/reportinfo?reportId=36844) and Haiti in August 2021 [8], and these reports occurred almost 40 years after the last outbreak of ASF in these countries. ASF has caused severe economic losses to the swine industry worldwide since the 1920s.

Classical swine fever virus (CSFV) is an enveloped single-stranded, positive-sense RNA virus that belongs to the Pestivirus genus of the Flaviviridae family [9]. CSFV causes classical swine fever (CSF), another notifiable disease of OIE, and it is characterized by high fever, leukopenia, extensive haemorrhage, convulsion and constipation or diarrhoea and presents high morbidity and mortality [10]. CSF was first reported in Ohio, USA, in 1833 , and it is still prevalent in many countries worldwide $[11,12]$. Although the Chinese C-strain vaccine of CSFV was developed in the 1950s and has been widely used in the field since then, CSF is still sporadic in many regions in China $[13,14]$. One explanation for this finding is that many circulating pathogens in China, such as PRRSV and PCV2, can cause immunosuppression [15, 16], which impairs the effect of vaccination with the $\mathrm{C}$-strain vaccine. Another reason is that the circulating CSFVs in the field have high genetic diversity $[17,18]$, which results in incomplete protection for pig herds even if vaccinated with the $\mathrm{C}$-strain vaccine.

Atypical porcine pestivirus (APPV), a newly discovered virus, is an enveloped single-stranded, positive-sense RNA virus that belongs to the Pestivirus genus of the Flaviviridae family [19]. It was first discovered in the USA in 2015 [20] and subsequently reported in many other countries in America, Asia and Europe [19, 21]. APPV is a possible causative agent of type A-II congenital tremor (CT) in newborn piglets, which is characterized by generalized body shaking with variable degrees of hypomyelination in the brain and spinal cord [20,22] and similar to type A-I CT caused by CSFV [23].

ASFV, CSFV and APPV are still prevalent in many countries and cause huge economic losses to the swine industry worldwide. ASF and CSF show similar clinical symptoms and pathological changes, such as high fever, leukopenia, extensive haemorrhage, constipation or diarrhoea, and high mortality [2, 10]. Type A-II CT caused by APPV shows similar clinical manifestations to type A-I CT caused by CSFV in newborn piglets [22, 23]. Therefore, differentiating these diseases in the field is difficult. Furthermore, ASFV, CSFV and APPV were simultaneously prevalent in some countries, and coinfections of these pathogens have been observed in pig herds $[24,25]$. Therefore, it is very important to differentially detect these pathogens by laboratory test methods for clinical diagnosis. Currently, several differential polymerase chain reaction (PCR)/reverse transcription (RT)-PCR and real-time quantitative PCR (qPCR)/ qRT-PCR assays have been developed for the detection of ASFV [26, 27], CSFV [28, 29], APPV [30], ASFV/ CSFV [31, 32] and ASFV/CSFV/APPV [24]. However, a qRT-PCR assay capable of simultaneous and differential detection of ASFV, CSFV and APPV has not been previously reported. Therefore, the objective of this study was to develop a specific, sensitive and reproducible one-step multiplex qRT-PCR for the simultaneous and differential detection of ASFV, CSFV and APPV.

\section{Results}

\section{Construction of standard recombinant plasmids}

The target fragments of the ASFV p72 gene, the CSFV $5^{\prime}$ untranslated region (UTR) and the APPV $5^{\prime} \mathrm{UTR}$, were amplified by PCR/RT-PCR, purified and ligated to the pMD18-T vector (TaKaRa, Dalian, China), and then transferred into E. coli $\mathrm{DH} 5 \alpha$ competent cells. The positive clones were cultured, and the plasmid constructs were extracted, and then their concentrations were determined by ultraviolet absorbance at $260 \mathrm{~nm}$ and $280 \mathrm{~nm}$. The results showed that the original concentrations of the three constructed plasmids, which were named p-ASFV, $\mathrm{p}-\mathrm{CSFV}$ and $\mathrm{p}$-APPV, were $2.65 \times 10^{10}$ copies $/ \mu \mathrm{L}$, $2.52 \times 10^{10}$ copies $/ \mu \mathrm{L}$, and $3.02 \times 10^{10}$ copies $/ \mu \mathrm{L}$, respectively. These plasmids were used as positive standard plasmids for the optimization of different reaction conditions and for sensitivity and repeatability of the multiplex qRT-PCR.

\section{Optimal parameters of the multiplex qRT-PCR}

After optimization, the reaction conditions, including the annealing temperature, primer and probe concentrations, amplification cycles, etc., were obtained. The reaction mixture of the developed multiplex qRT-PCR was as follows: $10 \mu \mathrm{L}$ of $2 \times$ One Step RT-PCR Buffer III (TaKaRa, Dalian, China), $0.4 \mu \mathrm{L}$ of Ex Taq HS (5 U/ $\mu \mathrm{L})(\mathrm{TaKaRa}$, Dalian, China), $0.4 \mu \mathrm{L}$ of PrimeScript RT Enzyme Mix II (RNA/DNA) (TaKaRa, Dalian, China), $0.4 \mu \mathrm{L}$ of each of ASFV, CSFV and APPV primers $(20 \mathrm{pmol} / \mu \mathrm{L}), 0.5 \mu \mathrm{L}$ of ASFV-p72-P $(20 \mathrm{pmol} / \mu \mathrm{L})$, 
$0.4 \mu \mathrm{L}$ of CSFV-5 ${ }^{\prime} \mathrm{UTR}-\mathrm{P}(20 \mathrm{pmol} / \mu \mathrm{L}), 0.3 \mu \mathrm{L}$ of APPV$5^{\prime}$ UTR-P $(20 \mathrm{pmol} / \mu \mathrm{L}), 2.0 \mu \mathrm{L}$ of total DNA/RNA, and distilled water to a total volume of $20 \mu \mathrm{L}$. The amplification parameters were as follows: reverse transcription at $42^{\circ} \mathrm{C}$ for $5 \mathrm{~min}$; inactivation at $95^{\circ} \mathrm{C}$ for $10 \mathrm{~s}$; and 40 cycles of denaturation at $95^{\circ} \mathrm{C}$ for $5 \mathrm{~s}$ and annealing and extension at $59^{\circ} \mathrm{C}$ for $34 \mathrm{~s}$. The fluorescent signals were determined at the end of each cycle.

\section{Standard curves of the multiplex qRT-PCR}

To generate the standard curves of the multiplex qRT-PCR, the standard plasmids of p-ASFV, p-CSFV and $\mathrm{p}$-APPV were mixed together and then serially diluted 10-fold to final concentrations of each plasmid of $2.52 \times 10^{8}$ to $2.52 \times 10^{0}$ copies $/ \mu \mathrm{L}\left(5.04 \times 10^{8}\right.$ to $5.04 \times 10^{0}$ copies per reaction). The results showed that the corresponding slope of the equation, correlation coefficient $\left(R^{2}\right)$, and amplification efficiency $(E)$ were $-3.065,0.999$, and $89.419 \%$ for ASFV, respectively; $-3.640,1.000$, and $88.256 \%$ for CSFV, respectively; and-3.716, 0.999 and $85.811 \%$ for APPV, respectively (Fig. 1). These results indicated that an excellent linear relationship $\left(R^{2} \geq 0.999\right)$ occurred between the initial template concentrations and the corresponding threshold cycle $(\mathrm{Ct})$ values.

\section{Specificity of the multiplex qRT-PCR}

To evaluate the specificity of the assay, the RNAs/DNAs of ASFV, CSFV, APPV, and 12 other viruses, namely, PCV2, PRV, PRRSV, FMDV, PPV, PEDV, TGEV, PRoV, PDCoV, BVDV-1, BVDV-2 and BDV, were used as templates for multiplex qRT-PCR. The results showed that ASFV, CSFV and APPV had specific amplification curves while the other 12 viruses did not demonstrate any fluorescent signal or amplification curve, indicating high specificity of the assay (Fig. 2).

\section{Sensitivity of the multiplex qRT-PCR}

The standard plasmids of p-ASFV, p-CSFV and p-APPV were mixed together and then serially diluted 10 -fold from $2.52 \times 10^{8}$ to $2.52 \times 10^{0}$ copies $/ \mu \mathrm{L}$ (final reaction concentrations: from $2.52 \times 10^{7}$ copies $/ \mu \mathrm{L}$ to $2.52 \times 10^{-1}$ copies $/ \mu \mathrm{L}$ ) and used to determine the sensitivity of the multiplex qRT-PCR. The results showed that the limit of detection (LOD) of the assay was $2.52 \times 10^{\circ}$ copies $/ \mu \mathrm{L}$ for ASFV, CSFV and APPV (Fig. 3), while the LOD of the corresponding singleplex qRT-PCR was also $2.52 \times 10^{0}$ copies $/ \mu \mathrm{L}$ for ASFV, CSFV and APPV, indicating that the multiplex qRTPCR had similar sensitivity as the singleplex qRT-PCR. The Ct values of the singleplex and multiplex qRT-PCR are shown in Table 1.

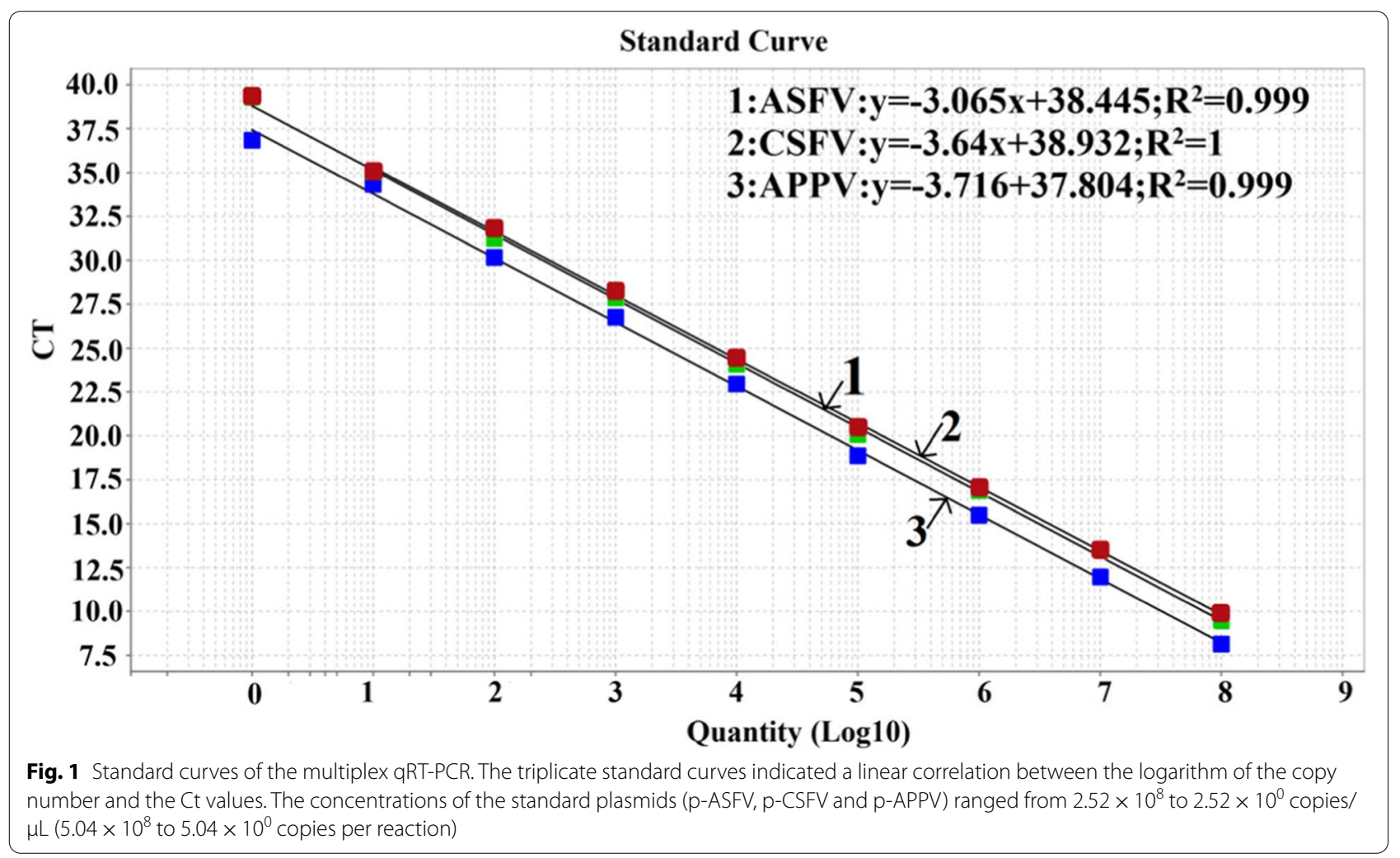




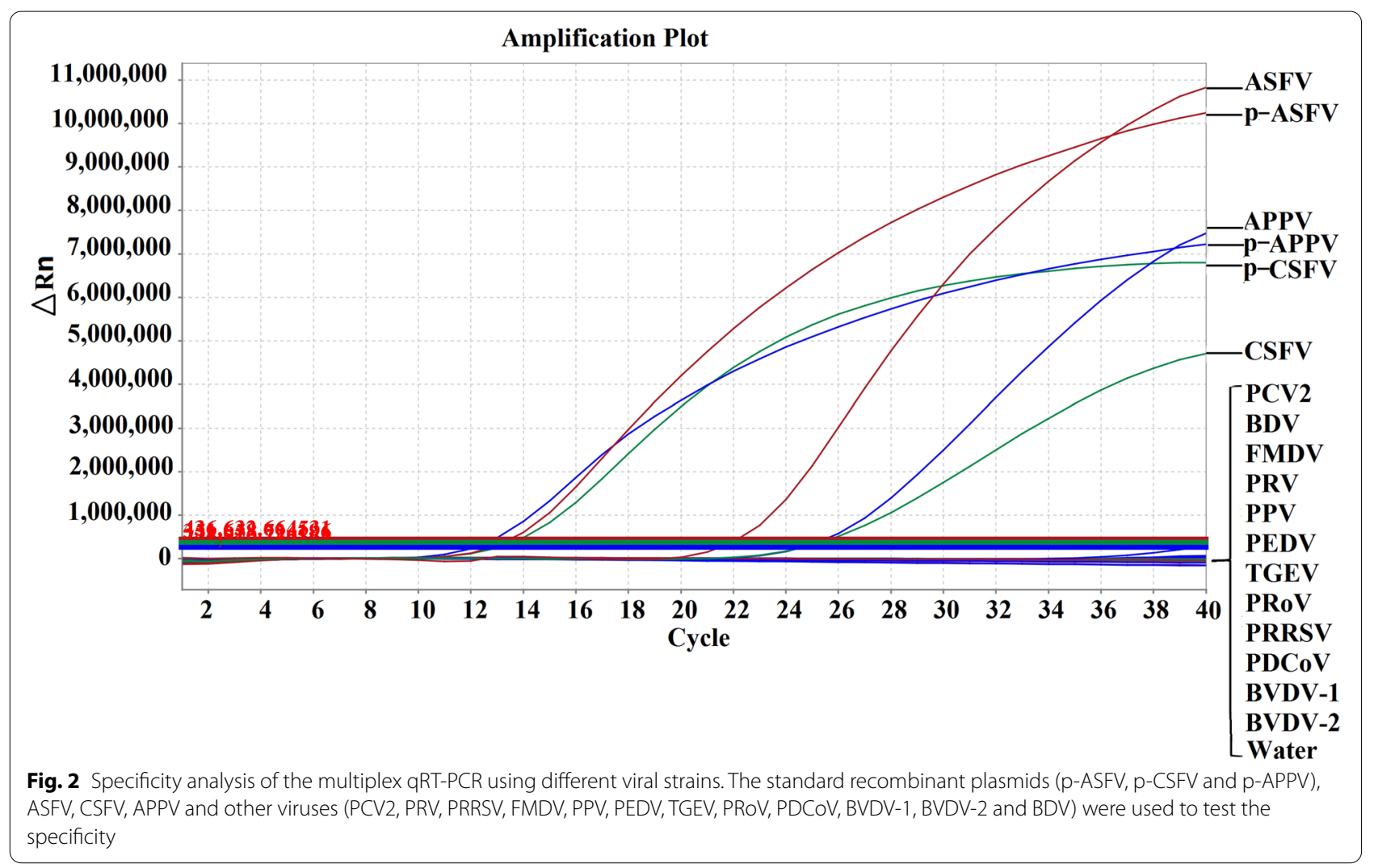

\section{Repeatability of the multiplex qRT-PCR}

To evaluate the repeatability of the assay, three concentrations of $2.52 \times 10^{7}, 2.52 \times 10^{5}$ and $2.52 \times 10^{3}$ copies $/ \mu \mathrm{L}$ (final reaction concentrations) of each standard plasmid in the mixtures were used as templates for the intra- and inter-assay comparisons. The results showed that the intra- and interassay coefficients of variation (CVs) of the $\mathrm{Ct}$ values were less than 2\% (Table 2), indicating high repeatability of the assay.

\section{Detection of clinical samples by multiplex qRT-PCR}

A total of 509 clinical samples collected from October 2018 to December 2020 in Guangxi Province, southern China, were detected by the developed multiplex qRTPCR to evaluate its practicality for the detection of clinical samples. The results showed that the positive rates of ASFV, CSFV and APPV were 45.58\% (232/509), 12.57\% $(64 / 509)$ and $3.54 \%(18 / 509)$, respectively, while the coinfection rates of ASFV and CSFV, ASFV and APPV, and CSFV and APPV were 4.91\% (25/509), 1.38\% (7/509), and $0.98 \%(5 / 509)$, respectively (Table 3$)$. The results detected by the established qRT-PCR were consistent with the results detected by the OIE-recommended real-time PCR/RT-PCR for ASFV and CSFV and the reported real-time RT-PCR for APPV [25] (Table 4). After the test, all samples were treated with high temperature and high pressure as required.

\section{Phylogenetic analysis based on ASFV p72 gene}

A total of 21 clinical samples were selected randomly from the ASFV-positive samples, and the C-terminal end of the B646L gene, which encodes the p72 major capsid protein of ASFV, was amplified and sequenced. Phylogenetic analysis based on partial p72 gene nucleotide sequences showed that 17 strains of the 21 strains obtained from Guangxi Province together with strains from Mozambique (MOZ-60-98, MAD/1/98, MAZ 9/2006), Tanzania (TAN 2011/01) and Zambia (LUS93-1) formed a distinguishable cluster belonging to genotype II, and the other 4 strains from Guangxi Province, together with strains from Nigeria (Nig01, NIG-2), Angola (Ang72), Congo (Kat67), Ghana (GHA/1/00), South Africa (ZAR85) and Cameroon (CAM/4/85) belonged to genotype I (Fig. 4).

\section{Discussion}

ASFV, CSFV and APPV are important pathogens in the swine industry. Coinfection between ASFV and CSFV might occur occasionally in certain pig herds, and the clinical manifestations and pathological changes between these viruses might be hard to distinguish in 

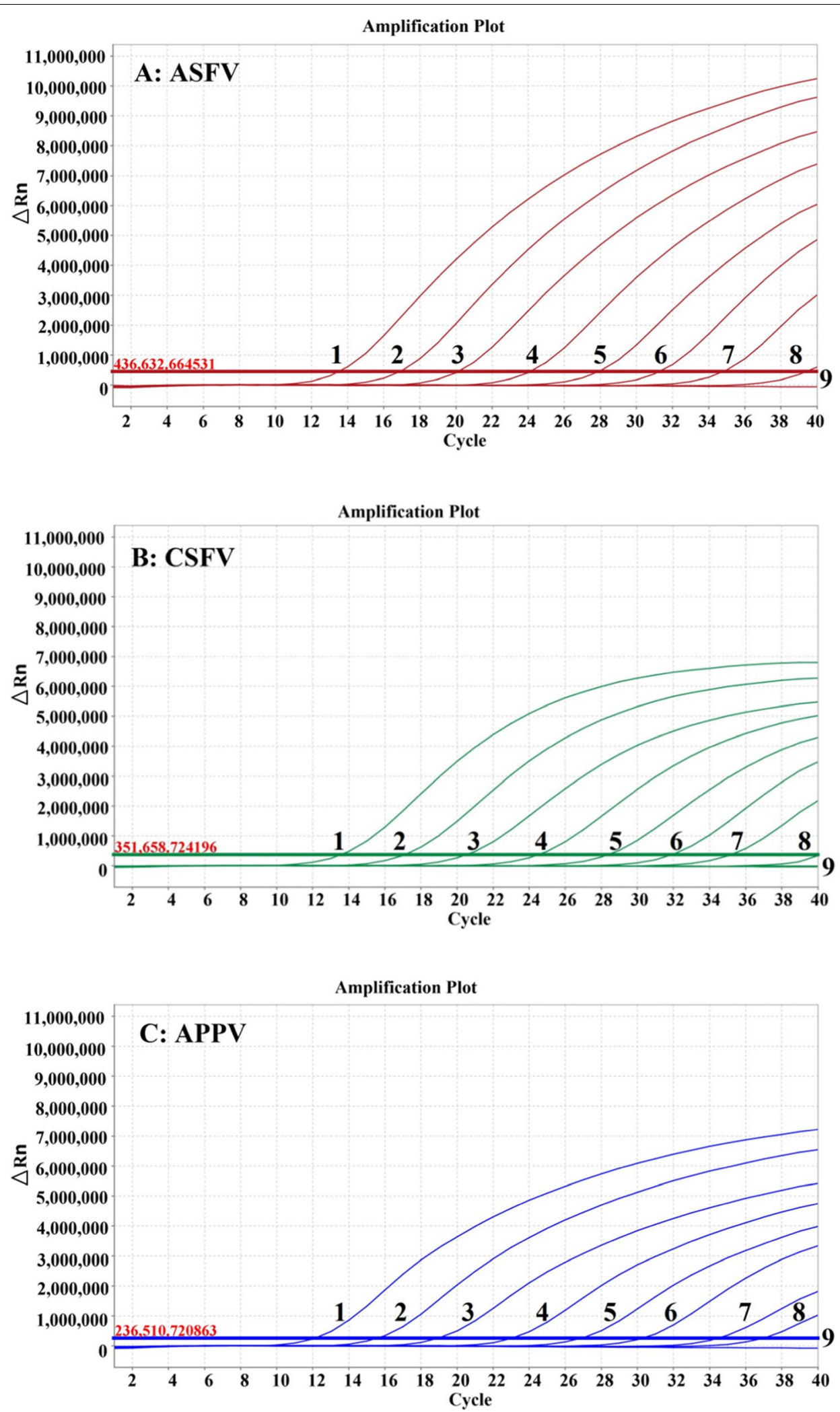

Fig. 3 Sensitivity analysis of the multiplex qRT-PCR. The standard recombinant plasmids ( $p-A S F V, p-C S F V$ and $p-A P P V)$ were used to test the sensitivity. 1-9: $2.52 \times 10^{7}-2.52 \times 10^{-1}$ copies/ $\mathrm{LL}$ (final reaction concentrations) 


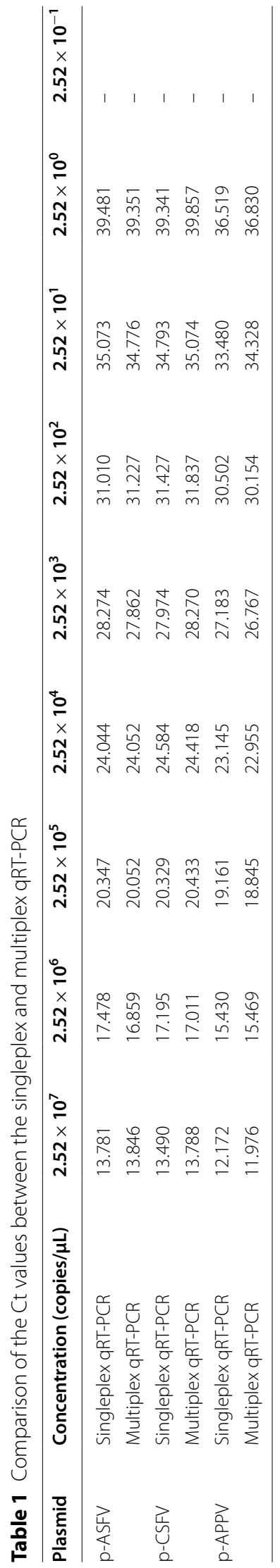


Table 2 Repeatability analysis of the multiplex qRT-PCR

\begin{tabular}{|c|c|c|c|c|c|c|c|}
\hline \multirow[t]{2}{*}{ Plasmid } & \multirow{2}{*}{$\begin{array}{l}\text { Concentration (copies/ } \\
\mu \mathrm{L} \text { ) }\end{array}$} & \multicolumn{3}{|c|}{ Ct values of intra-assay } & \multicolumn{3}{|c|}{ Ct value of inter-asssay } \\
\hline & & $\bar{x}$ & SD & CV (\%) & $\bar{x}$ & SD & CV (\%) \\
\hline \multirow[t]{3}{*}{ p-ASFV } & $2.52 \times 10^{3}$ & 27.847 & 0.370 & 1.329 & 27.942 & 0.379 & 1.356 \\
\hline & $2.52 \times 10^{5}$ & 20.738 & 0.168 & 0.810 & 20.747 & 0.207 & 0.998 \\
\hline & $2.52 \times 10^{7}$ & 13.845 & 0.166 & 1.199 & 13.725 & 0.124 & 0.903 \\
\hline \multirow[t]{3}{*}{ P-CSFV } & $2.52 \times 10^{3}$ & 28.001 & 0.153 & 0.546 & 27.946 & 0.186 & 0.666 \\
\hline & $2.52 \times 10^{5}$ & 20.359 & 0.200 & 0.982 & 20.457 & 0.239 & 1.168 \\
\hline & $2.52 \times 10^{7}$ & 13.109 & 0.156 & 1.190 & 13.076 & 0.088 & 0.673 \\
\hline \multirow[t]{3}{*}{ P-APPV } & $2.52 \times 10^{3}$ & 27.328 & 0.152 & 0.556 & 27.314 & 0.137 & 0.502 \\
\hline & $2.52 \times 10^{5}$ & 19.125 & 0.267 & 1.396 & 19.128 & 0.207 & 1.082 \\
\hline & $2.52 \times 10^{7}$ & 12.348 & 0.145 & 1.174 & 12.302 & 0.157 & 1.276 \\
\hline
\end{tabular}

Table 3 Detection of clinical samples by the multiplex qRT-PCR

\begin{tabular}{|c|c|c|c|c|c|c|c|}
\hline Date & Numbers & ASFV (\%) & CSFV (\%) & APPV (\%) & ASFV+CSFV (\%) & ASFV+APPV (\%) & CSFV+APPV (\%) \\
\hline Oct, 2018 & 18 & $0(0)$ & $2(11.11)$ & $1(5.56)$ & $0(0)$ & $0(0)$ & $0(0)$ \\
\hline Nov, 2018 & 40 & $0(0)$ & $9(22.5)$ & $4(10.00)$ & $0(0)$ & $0(0)$ & $1(2.50)$ \\
\hline Dec, 2018 & 30 & $5(16.67)$ & $6(20.00)$ & $1(3.33)$ & $3(10.00)$ & $0(0)$ & $1(3.33)$ \\
\hline Jan, 2019 & 38 & $5(13.16)$ & $4(10.53)$ & $0(0)$ & $1(2.63)$ & $0(0)$ & $0(0)$ \\
\hline Feb, 2019 & 57 & $15(26.32)$ & $5(8.77)$ & $3(5.26)$ & $3(5.26)$ & $2(3.51)$ & $1(1.75)$ \\
\hline Mar, 2019 & 36 & $10(27.78)$ & $7(19.44)$ & $0(0)$ & $4(11.11)$ & $0(0)$ & $0(0)$ \\
\hline Apr, 2019 & 19 & $12(63.16)$ & $3(15.79)$ & $1(5.26)$ & $0(0)$ & $0(0)$ & $0(0)$ \\
\hline May, 2019 & 16 & $16(100.00)$ & $0(0)$ & $2(12.50)$ & $0(0)$ & $1(6.25)$ & $0(0)$ \\
\hline Jun, 2019 & 11 & $4(36.36)$ & $1(9.09)$ & $1(9.09)$ & $0(0)$ & $1(9.09)$ & $0(0)$ \\
\hline Jul, 2019 & 12 & $12(100.00)$ & $2(16.67)$ & $0(0)$ & $0(0)$ & $0(0)$ & $0(0)$ \\
\hline Aug, 2019 & 28 & $20(71.43)$ & $2(7.14)$ & $0(0)$ & $2(7.14)$ & $0(0)$ & $0(0)$ \\
\hline Sep, 2019 & 15 & $15(100.00)$ & $2(13.33)$ & $0(0)$ & $2(13.33)$ & $0(0)$ & $0(0)$ \\
\hline Oct, 2019 & 20 & $20(100.00)$ & $1(5.00)$ & $0(0)$ & $1(5.00)$ & $0(0)$ & $0(0)$ \\
\hline Nov, 2019 & 24 & $21(87.50)$ & $5(20.83)$ & $3(12.50)$ & $5(20.83)$ & $3(12.50)$ & $2(8.33)$ \\
\hline Dec, 2019 & 10 & $6(60.00)$ & $1(10.00)$ & $0(0)$ & $0(0)$ & $0(0)$ & $0(0)$ \\
\hline Jan, 2020 & 10 & $10(100.00)$ & $0(0)$ & $0(0)$ & $0(0)$ & $0(0)$ & $0(0)$ \\
\hline Feb, 2020 & 10 & $7(70.00)$ & $1(10.00)$ & $0(0)$ & $0(0)$ & $0(0)$ & $0(0)$ \\
\hline Jul, 2020 & 4 & $0(0)$ & $4(100.00)$ & $0(0)$ & $0(0)$ & $0(0)$ & $0(0)$ \\
\hline Aug, 2020 & 10 & $8(80.00)$ & $0(0)$ & $0(0)$ & $0(0)$ & $0(0)$ & $0(0)$ \\
\hline Sep, 2020 & 26 & $14(53.85)$ & $2(7.69)$ & $0(0)$ & $0(0)$ & $0(0)$ & $0(0)$ \\
\hline Oct, 2020 & 20 & $13(65.00)$ & $6(30.00)$ & $0(0)$ & $4(20.00)$ & $0(0)$ & $0(0)$ \\
\hline Nov, 2020 & 32 & $15(46.88)$ & $1(3.13)$ & $0(0)$ & $0(0)$ & $0(0)$ & $0(0)$ \\
\hline Dec, 2020 & 23 & 4 (17.39) & $0(0)$ & $2(8.70)$ & $0(0)$ & $0(0)$ & $0(0)$ \\
\hline Total & 509 & $232(45.58)$ & 64 (12.57) & $18(3.54)$ & $25(4.91)$ & $7(1.38)$ & $5(0.98)$ \\
\hline
\end{tabular}

the field; moreover, similar phenomena are observed between CSFV and APPV [2, 10, 21, 22, 24, 25]. Highly virulent ASFVs of genotype II were first identified in China in August 2018 and have become the main epidemic genotype [33]. However, two strains of genotype I ASFV were recently identified in China, and one strain showed low virulence and efficient transmissibility in pigs and caused mild onset of infection and chronic disease [34], which increased the difficulty of differentially diagnosing ASF and CSF in the field. Therefore, to accurately diagnose these diseases, it is necessary to differentially detect these pathogens in the laboratory and obtain clinical information. Among the many diagnostic methods, qRT-PCR is undoubtedly one of the best choices because it is a rapid, specific, sensitive and accurate method for the detection of viral nucleic acids 
Table 4 Agreement between the multiplex qRT-PCR and the reference methods

\begin{tabular}{llll}
\hline Detection method & \multicolumn{3}{l}{ Number of positive samples } \\
\cline { 2 - 4 } & ASFV & CSFV & APPV \\
\hline Multiplex qRT-PCR & $232 / 509$ & $64 / 509$ & $18 / 509$ \\
Reference methods & $232 / 509$ & $64 / 509$ & $18 / 509$ \\
Agreements & $100 \%$ & $100 \%$ & $100 \%$ \\
\hline
\end{tabular}

Note: the reference methods refer to the real-time PCR/RT-PCR that was recommended for ASFV (Chapter 3.9.1), CSFV (Chapter 3.9.3) identification by the OIE (OIE Terrestrial Manual 2019) and the real-time RT-PCR for detection of APPV reported by Liu et al. with modification [25]

and can be conveniently used for the quantification and detection of swine viral pathogens $[35,36]$. Due to its high throughput, sensitivity, accuracy and ability to detect several pathogens in one reaction within a very short time, multiplex qRT-PCR has been widely used for diagnostic purposes in veterinary laboratories in China. Therefore, a one-step multiplex qRT-PCR was developed to differentially detect ASFV, CSFV and APPV in this study. The assay could specifically detect ASFV, CSFV and APPV with an LOD of $2.52 \times 10^{1}$ copies $/ \mu \mathrm{L}$ for each pathogen, and the intra- and interassay CVs were all less than $2 \%$, thus showing high specificity, sensitivity and repeatability. Finally, the developed assay was used to detect 509 clinical samples to further verify its practicality for the detection of samples collected in the field.

The developed qRT-PCR was used to detect 509 clinical samples from Guangxi Province, southern China, for ASFV, CSFV and APPV. The results showed that the positive rates of ASFV, CSFV and APPV were $45.58,12.57$ and $3.54 \%$, respectively, indicating that these viruses were still widely prevalent in pig herds in southern China. Since ASFV and CSFV can cause huge economic damage to the swine industry, great efforts to prevent and control these viruses are required. Furthermore, the coinfection rates of ASFV/ CSFV, ASFV/APPV and CSFV/APPV were 4.91, 1.38 and $0.98 \%$, respectively, indicating that coinfections of ASFV, CSFV and APPV were common in certain pig herds. The results were similar to our previous report [25]. Since coinfection of ASFV and CSFV could exacerbate the manifestations and pathological changes [24], with ASFV potentially suppressing the immune response of pig herds vaccinated with the CSFV vaccine [37], the epidemic situation and economic losses will be aggravated. Moreover, it is very important to accurately detect pathogens and rapidly eliminate infected pigs in the early stage. Wildtype and gene-deleted ASFV strains were recently identified in the field from several provinces in China $[38,39]$. To ensure that the established qRT-PCR could detect both of these strains, the B646L gene (p72 gene), which is a conserved region for all ASFVs, was selected as a targeting gene to design the specific primers and probes, and the sequences were further blasted in the NCBI database to ensure their conservation to all ASFVs and their specificity to all other viruses. The results in this study showed the high specificity, sensitivity, repeatability and practicality of the developed qRT-PCR. Therefore, the developed multiplex qRT-PCR in this study could provide a useful tool for the rapid differentiation of ASFV, CSFV and APPV in clinical samples from suspected pigs.

ASF was first identified in China in August 2018 and subsequently reported in other Asian countries [8], and it has caused huge economic losses to the swine industry. Since ASF is a newly emergent disease in China and has spread rapidly across this country [7], it is very interesting to study the genomic characteristics of ASFV. The ASFV genome varies by approximately 170 to $193 \mathrm{~kb}$ and encodes 150 to 167 kinds of proteins [40]. Based on partial p72 gene sequences, ASFV strains from different countries are currently classified into 24 genotypes and divided into three lineages [41]. The 21 ASFV strains from Guangxi Province evaluated in this study shared a high level of nucleotide homology $(97.3 \% \sim 100 \%)$ and amino acid identity $(83.4 \% \sim 95.1 \%)$ with strains from different countries in the world (data not shown). Phylogenetic analysis based on partial p72 gene nucleotide sequences revealed that all ASFV strains from Guangxi Province belonged to two genotypes (genotypes I and II), with most of these strains (17 of 21 strains) grouped into genotype II and the other strains (4 of 17 strains) grouped into genotype I. The results showed that genotype I and II ASFV strains were simultaneously prevalent in Guangxi Province, which increased the complexity of circulating strains and made it harder to prevent and control. To our knowledge, this is the first report showing the prevalence of genotype I ASFV in southern China. To date, two of the 24 currently described ASFV genotypes based on the p72 gene sequence, namely, genotypes I and II, have been reported outside Africa [42]. Recently, genotype I and II ASFVs epidemics were reported in several provinces in China, with genotype I showing decreased virulence and caused mild manifestations and pathological changes [43]. Furthermore, genotype II ASFV strains might enable domestic pigs and wild boars to develop chronic infections and become carriers after recovery [44]. According to the surveillance results in this study, genotype II ASFVs were the main circulating strains 


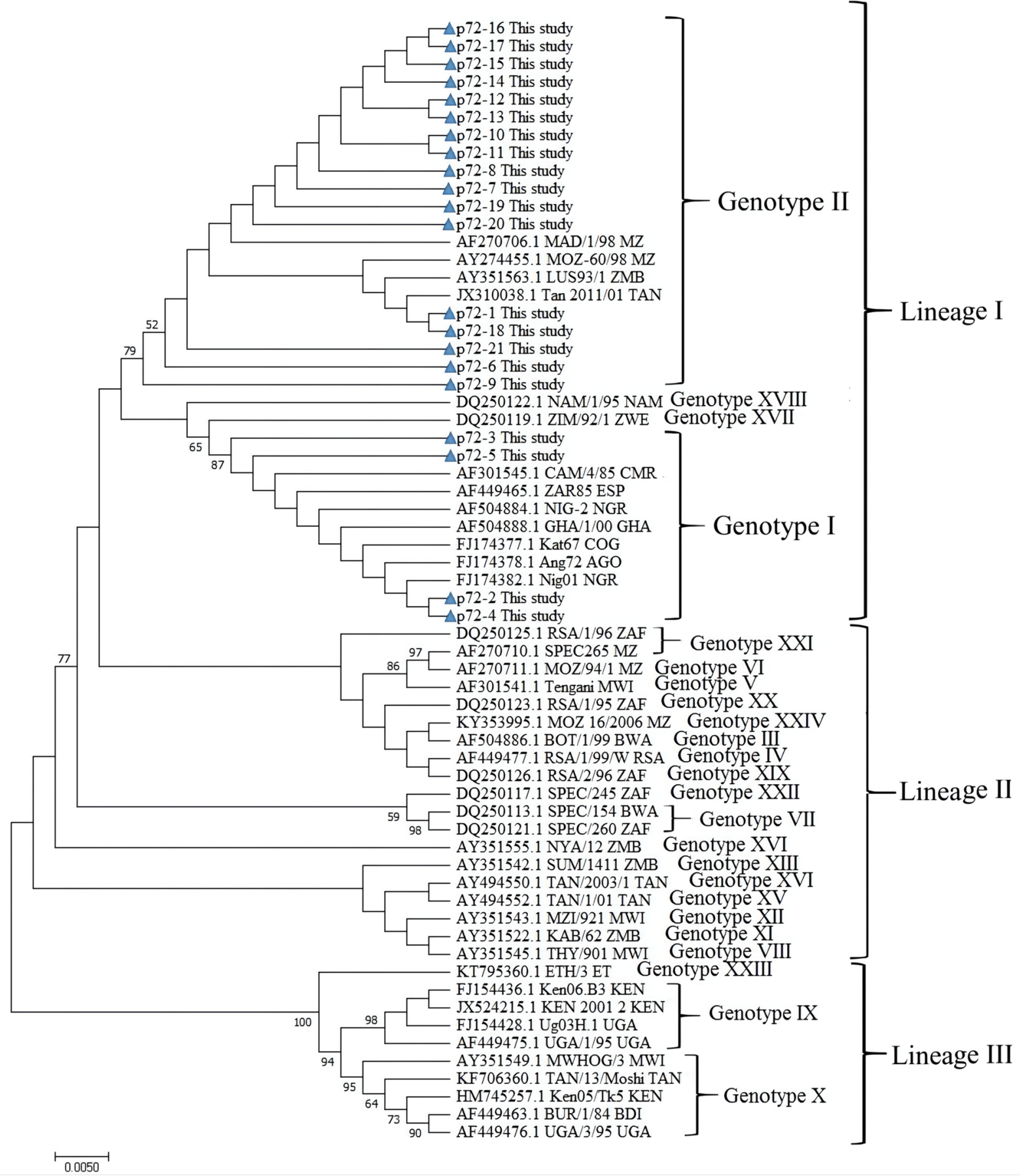

Fig. 4 Phylogenetic tree based on partial p72 gene of ASFV. The tree was constructed using the neighbour-joining algorithm of MEGA5.0, and 1000 bootstrap replicates were performed to assign confidences to the groupings. The strains from this study were marked with triangle $(\triangle)$

in Guangxi Province, although genotype I ASFVs were also prevalent in pig herds. The circulation of different genotypes of ASFV in the field will increase the complexity of the disease and the difficulty of its control and prevention. More attention should be given to clinical surveillance to remain abreast of the molecular characteristics and genetic diversity of epidemic ASFV strains in the field. 


\section{Conclusion}

In this study, specific primers and probes were designed according to the genomic sequences of ASFV, CSFV and APPV. After optimizing the reaction conditions, including the primer and probe concentrations, annealing temperature, amplification cycles, etc., a one-step multiplex qRT-PCR with high specificity, sensitivity and repeatability was successfully developed for simultaneous and differential detection of ASFV, CSFV and APPV. The ASFV strains from Guangxi Province belonged to genotypes I and II according to the phylogenetic tree, which was based on the nucleotide sequence of the ASFV p72 gene. Thus, the results indicate that at least two genotypes of ASFV are currently prevalent in Guangxi Province, southern China.

\section{Methods}

Viruses and clinical samples

CSFV (C vaccine strain), PCV2 (SX07 vaccine strain), PRRSV (TJM-F92 vaccine strain), FMDV (O/Mya98/ $\mathrm{XJ} / 2010$ vaccine strain), PRV (Bartha-K61 vaccine strain), PPV ( $\mathrm{N}$ vaccine strain), PEDV (CV777 vaccine strain), TGEV ( $\mathrm{H}$ vaccine strain), and PRoV (NX vaccine strain) were stored in our laboratory. ASFV-, APPV-, BVDV-1-, BVDV-2-, BDV- and PDCoV-positive clinical samples were collected in the field, confirmed by PCR/RT-PCR and gene sequencing, and stored in our laboratory.

A total of 509 clinical samples, including brain, lung, liver, spleen and lymph nodes from each dead pig, were collected from different pig herds in Guangxi Province, southern China, from October 2018 to December 2020. All clinical samples were stored at $-80^{\circ} \mathrm{C}$ until used.

\section{Primers and TaqMan probes}

Three pairs of specific primers and corresponding TaqMan probes used for multiplex qRT-PCR assays were designed using Primer Express 3.0 software (ABI, USA) based on the genomic sequences of ASFV (GenBank accession number NC_001659), CSFV (NC_002657) and APPV (KY624591), with a 79bp fragment amplified for the ASFV p72 gene, a $72 \mathrm{bp}$ fragment amplified for the CSFV 5'UTR and a $90 \mathrm{bp}$ fragment amplified for the APPV 5'UTR. The sequences of the designed primers and probes were analysed using the Blast tool from the National Center for Biotechnology Information (NCBI) and information on published sequences to confirm the high conservation of primers and probes among different reference strains of ASFV, CSFV and APPV. Detailed information on the primers and probes is listed in Table 5.

\section{Extraction of nucleic acid}

All vaccine viruses and the pooled clinical tissue homogenates $(20 \%, \mathrm{~W} / \mathrm{V})$ were resuspended in phosphate-buffered saline (PBS, pH7.2), vortexed and centrifuged at $12,000 \times \mathrm{g}$ at $4{ }^{\circ} \mathrm{C}$ for $5 \mathrm{~min}$. Total RNA and DNA were extracted from the supernatants using MiniBEST RNA/ DNA Extraction Kit Ver. 5.0 (TaKaRa, Dalian, China) according to the manufacturer's instructions and stored at $-80^{\circ} \mathrm{C}$ until use.

\section{Construction of standard plasmids}

Total DNA was extracted from ASFV-positive samples, and total RNA was extracted from CSFV vaccine- and APPV-positive samples and then reverse transcribed to cDNA. The target fragments of ASFV, CSFV and APPV were amplified by PCR using ASFV DNA and CSFV and APPV cDNA as templates. The amplicons were purified and cloned into the pMD18-T vector (TaKaRa, Dalian, China) and transferred into $E$. coli DH5 $\alpha$ competent cells (TaKaRa, Dalian, China). The positive clones were cultured at $37^{\circ} \mathrm{C}$ for $18 \mathrm{~h}-20 \mathrm{~h}$ and extracted by a MiniBEST Plasmid Extraction Kit Ver. 5.0 (TaKaRa, Dalian, China) for the plasmid constructs. The plasmids were named

Table 5 Primers and probes used for detection of ASFV, CSFV and APPV

\begin{tabular}{ll}
\hline Primer and probe & Sequence $\left(\mathbf{5}^{\prime} \rightarrow \mathbf{3}^{\prime}\right)$ \\
\hline ASFV-p72-F & $\begin{array}{c}\text { Product } \\
\text { size } \mathbf{( b p )}\end{array}$ \\
ASFV-p72-R & GGCGTATAAAAAGTCCAGGAAATTC \\
ASFV-p72-P & TTCGGCGAGCGCTTTATC \\
CSFV-5'UTR-F & Texas Red-TCACCAAATCCTTTTGCGATGCAAGCT-BHQ2 \\
CSFV-5'UTR-R & CCTGAGTACAGGACAGTCGTCAGT \\
CSFV-5'UTR-P & CCCTCGTCCACATAGCATCTC \\
APPV-5'UTR-F & JOE-TTCGACGTGAGCAGAAGCCCACC-BHQ1 \\
APPV-5'UTR-R & GGCGTGCCCAAAGAGAATT \\
APPV-5'UTR-P & GGCACTCTATCAAGCAGTAAGGTCTA \\
\hline
\end{tabular}


p-ASFV, p-CSFV and p-APPV and stored at $-80^{\circ} \mathrm{C}$ until use as standard plasmids.

The standard plasmids were quantified by ultraviolet absorbance at $260 \mathrm{~nm}$ and $280 \mathrm{~nm}$ with a NanoDrop spectrophotometer (Thermo Fisher, USA). The exact copy numbers of plasmids were calculated using the following formula: maximum $\Delta \mathrm{Rn}$ and minimal $\mathrm{C}_{\mathrm{t}}$ values using standard plasmids of different dilutions as templates.

\section{Specificity analysis of the multiplex qRT-PCR}

The DNA or RNA of ASFV, CSFV, APPV, PCV2, PRV, PRRSV, PPV, FMDV, PEDV, TGEV, PRoV, PDCoV, BVDV-1, BVDV-2 and BDV was used as templates of the developed multiplex qRT-PCR to verify the specificity of the assay.

Plasmid copies $/ \mu L=\left(6.02 \times 10^{23}\right) \times\left(\mathrm{X} \mathrm{ng} / \mu L \times 10^{-9}\right) /$ plasmid length $(\mathrm{bp}) \times 660$

\section{Optimization of the singleplex qRT-PCR assay}

The standard plasmids were mixed together and then serially diluted 10 -fold from $2.52 \times 10^{9}$ copies/ $\mu \mathrm{L}$ to $2.52 \times 10^{1}$ copies $/ \mu \mathrm{L}$ (final reaction concentrations: $2.52 \times 10^{8}$ copies $/ \mu \mathrm{L}$ to $2.52 \times 10^{0}$ copies $/ \mu \mathrm{L}$ ) to optimize the reaction conditions of the singleplex qRT-PCR of ASFV, CSFV and APPV. The reaction mixture contained $2 \times$ One Step qRT-PCR Buffer III (TaKaRa, Dalian, China) $10 \mu \mathrm{L}$, Ex Taq HS $(5 \mathrm{U} / \mu \mathrm{L})$ (TaKaRa, Dalian, China) $0.4 \mu \mathrm{L}$, PrimeScript RT Enzyme Mix II (TaKaRa, Dalian, China) $0.4 \mu \mathrm{L}$, each primer $0.1-0.6 \mu \mathrm{L}$, each probe $0.1-0.6 \mu \mathrm{L}$, plasmid template $2.0 \mu \mathrm{L}$ and distilled water to a total volume of $20 \mu \mathrm{L}$. All reactions were amplified by an ABI QuantStudio ${ }^{\mathrm{TM}} 6$ Real-time System (ABI, USA), and the amplification parameters were as follows: $42^{\circ} \mathrm{C}$ for $5 \mathrm{~min} ; 95^{\circ} \mathrm{C}$ for $10 \mathrm{~s}$; and then 40 cycles of $95^{\circ} \mathrm{C}$ for $5 \mathrm{~s}$ and $59^{\circ} \mathrm{C}$ for $34 \mathrm{~s}$. The fluorescent signals were determined at the end of each cycle.

\section{Optimization of the multiplex qRT-PCR assay}

Based on the optimal reaction conditions of the singleplex qRT-PCR, the reaction conditions of the multiplex qRT-PCR, including annealing temperature, primer concentrations, probe concentrations, amplification cycles, etc., were further determined by orthogonal experiments.

The reaction mixture contained $10 \mu \mathrm{L}$ of $2 \times$ One Step qRT-PCR Buffer III (TaKaRa, Dalian, China), $0.4 \mu \mathrm{L}$ of Ex Taq HS $(5 \mathrm{U} / \mu \mathrm{L})$ (TaKaRa, Dalian, China), $0.4 \mu \mathrm{L}$ of PrimeScript RT Enzyme Mix II (TaKaRa, Dalian, China), $0.1-0.6 \mu \mathrm{L}$ of the primer and probe mixture with different final concentrations, $2.0 \mu \mathrm{L}$ of the three standard plasmids (mixed in a ratio of 1:1:1) with different final concentrations as templates, and sterilized distilled water to a final volume of $20 \mu \mathrm{L}$. The amplification parameters were as follows: $42^{\circ} \mathrm{C}$ for $5 \mathrm{~min}$; incubation at $95^{\circ} \mathrm{C}$ for $10 \mathrm{~s}$; and then 40 cycles of denaturation at $95^{\circ} \mathrm{C}$ for $5 \mathrm{~s}$ and annealing and extension at $59^{\circ} \mathrm{C}$ for $34 \mathrm{~s}$. Finally, the fluorescent signals were determined at the end of each cycle. After amplification, a Ct value was assigned to each sample. The final concentrations of primers, probes and amplification conditions were optimized to obtain the

\section{Sensitivity analysis of the multiplex qRT-PCR}

The standard plasmids of p-ASFV, p-CSFV and p-APPV were mixed together and then serially diluted 10-fold from $2.52 \times 10^{8}$ copies $/ \mu \mathrm{L}$ to $2.52 \times 10^{0}$ copies $/ \mu \mathrm{L}$ (final reaction concentrations: $2.52 \times 10^{7}$ copies $/ \mu \mathrm{L}$ to $2.52 \times 10^{-1}$ copies $/ \mu \mathrm{L}$ ) and used as templates for multiplex qRT-PCR to determine the sensitivity of the assay.

\section{Repeatability analysis of the multiplex qRT-PCR}

The standard plasmids of p-ASFV, p-CSFV and p-APPV were mixed together and then serially diluted 10-fold from $2.52 \times 10^{8}$ copies $/ \mu \mathrm{L}$ to $2.52 \times 10^{0}$ copies $/ \mu \mathrm{L}$, and concentrations of $2.52 \times 10^{8}$ copies $/ \mu \mathrm{L}, 2.52 \times 10^{6}$ copies $/ \mu \mathrm{L}$ and $2.52 \times 10^{4}$ copies $/ \mu \mathrm{L}$ (final reaction concentrations: $2.52 \times 10^{7}$ copies $/ \mu \mathrm{L}, 2.52 \times 10^{5}$ copies $/ \mu \mathrm{L}$ and $2.52 \times 10^{3}$ copies $/ \mu \mathrm{L}$ ) were used as templates for the developed multiplex qRT-PCR. The intra-assay was performed in triplicate, and the inter-assay was repeated three times, with an interval of 1 week. The intra- and inter-assay CVs were determined to evaluate the repeatability of the assay.

\section{Detection of clinical samples by multiplex qRT-PCR}

A total of 509 clinical samples were collected from pig farms in Guangxi Province, southern China, from October 2018 to December 2020. Total RNA and DNA were extracted from $20 \%$ tissue supernatants using a MiniBEST RNA/DNA Extraction Kit Ver. 5.0 (TaKaRa, Dalian, China) and detected by the developed multiplex qRT-PCR for ASFV, CSFV and APPV. The above templates were also detected by real-time PCR/RT-PCR, as recommended for ASFV (Chapter 3.9.1) and CSFV (Chapter 3.9.3) identification by the OIE (OIE Terrestrial Manual 2019), and detected by real-time RT-PCR, as reported for the detection of APPV with modification [25].

\section{Phylogenetic analysis based on ASFV p72 gene}

Twenty-one samples were selected randomly from the positive ASFV samples to amplify a partial p72 gene using a pair of primers (P72-U: $5^{\prime}$-GGCACA AGTTCGGACATGT-3', P72-D: 5'-GTACTGTAA 
CGCAGCACAG-3') as previously described [45]. The $\mathrm{PCR}$ products were purified, ligated to the $\mathrm{PMD}-18 \mathrm{~T}$ vector (TaKaRa, Dalian, China) and transferred to $E$. coli DH5 $\alpha$ competent cells. The positive clones were selected and sequenced (TaKaRa, Dalian, China), and the acquired sequences were edited by the EditSeq program of DNAstar software and aligned with the reference strains retrieved from GenBank using ClustalW. Phylogenetic reconstruction was conducted using the maximum-likelihood algorithm method $(\mathrm{T} 92+\mathrm{G})$. Phylogenetic tree reliability was supported using the Kimura distances and a bootstrap method with 1000 replications.

\begin{abstract}
Abbreviations
APPV: Atypical porcine pestivirus; ASFV: African swine fever virus; BDV: Border disease virus; BVDV: Bovine viral diarrhea virus; CSFV: Classical swine fever virus; $\mathrm{CV}$ : Coefficient of variation; FMDV: Foot-and-mouth disease virus; LOD: Limit of detection; multiplex qRT-PCR: Multiplex real-time quantitative RT-PCR; OIE: The World Organization for Animal Health; PCV2: Porcine circovirus type 2; PDCoV: Porcine deltacoronavirus; PEDV: Porcine epidemic diarrhoea virus; PPV: Porcine parvovirus; PRRSV: Porcine reproductive and respiratory syndrome virus; PRV: Pseudorabies virus; TGEV: Transmissible gastroenteritis virus; PRoV: Porcine rotavirus; RT-PCR: Reverse-transcription polymerase chain reaction.
\end{abstract}

\section{Acknowledgements}

We are grateful to Guangxi Center for Animal Disease Control and Prevention (CADC) for providing all the viral strains and clinical samples used in this study. Guangxi CADC was approved by Ministry of Agriculture and Rural Affairs of the People's Republic of China for collection and detection of ASFV in clinical samples (Approval number: 2018-154-25).

\section{Authors' contributions}

LHX carried out the experiments, data analysis and drafted the manuscript. SKC initiated the research program, and contributed to manuscript revision and final presentation. ZJ and CYT helped to perform the experiments. YYW and LWJ participated in sample collection. SHB revised the manuscript. QSJ and LF participated in clinical data acquisition. All authors have read and approved the final manuscript.

\section{Funding}

This work was supported by Guangxi Science and Technology Bureau, China (AB21238003, AA17204057) and Guangxi Agriculture and Rural Affairs Bureau, China (Z201954, Z202031). The funding sources had no involvement in the design of the research, the collection, analysis and interpretation of data, and the writing of the manuscript.

\section{Availability of data and materials}

All data generated or analyzed during this study are included in this article and are available from the corresponding author on reasonable request.

\section{Declarations}

\section{Ethics approval and consent to participate}

The programs and procedures used in this study have been examined and approved by Guangxi CADC, China. We obtained written informed consent to use the clinical samples in our study from the owners of the animals.

\section{Consent for publication}

Not applicable.

\section{Competing interests}

The authors declare that they have no competing interests.
Received: 5 May 2021 Accepted: 6 January 2022

Published online: 18 January 2022

\section{References}

1. Alonso C, Borca M, Dixon L, Revilla Y, Rodriguez F, Escribano JM. ICTV report consortium. ICTV virus taxonomy profile: Asfarviridae. J Gen Virol. 2018;99(5):613-4.

2. Dixon LK, Sun H, Roberts H. African swine fever. Antivir Res. 2019;165:34-41.

3. Cwynar P, Stojkov J, Wlazlak K. African swine fever status in Europe. Viruses. 2019;11(4):310.

4. Sanchez-Vizcaino JM, Mur L, Martinez-Lopez B. African swine fever: an epidemiological update. Transbound Emerg Dis. 2012;59(Suppl 1):27-35.

5. Zhou X, Li N, Luo Y, Liu Y, Miao F, Chen T, et al. Emergence of African swine fever in China, 2018. Transbound Emerg Dis. 2018;65(6):1482-4.

6. Tao D, Sun D, Liu Y, Wei S, Yang Z, An T, et al. One year of African swine fever outbreak in China. Acta Trop. 2020;211:105602.

7. Mighell E, Ward MP. African swine fever spread across Asia, 2018-2019. Transbound Emerg Dis. 2021;68(5):2722-32.

8. Stepien M, Cole L. USDA statement on confirmation of African swine fever in Haiti. Washington D. C.: USDA APHIS; 2021. https://www.aphis. usda.gov/aphis/newsroom/stakeholder-info/sa_by_date/sa-2021/sa-09/ asf-haiti

9. Brown VR, Bevins SN. A review of classical swine fever virus and routes of introduction into the United States and the potential for virus establishment. Front Vet Sci. 2018:5:31.

10. Smith DB, Meyers G, Bukh J, Gould EA, Monath T, Scott Muerhoff A, et al. Proposed revision to the taxonomy of the genus Pestivirus, family Flaviviridae. J Gen Virol. 2017;98(8):2106-12.

11. Coronado L, Perera CL, Rios L, Frias MT, Perez LJ. A critical review about different vaccines against classical swine fever virus and their repercussions in endemic regions. Vaccines (Basel). 2021;9(2):154.

12. Ganges L, Crooke HR, Bohórquez JA, Postel A, Sakoda Y, Becher P, et al. Classical swine fever virus: the past, present and future. Virus Res. 2020;289:198151.

13. Luo Y, Ji S, Lei JL, Xiang GT, Liu Y, Gao Y, et al. Efficacy evaluation of the C-strain-based vaccines against the subgenotype 2.1 d classical swine fever virus emerging in China. Vet Microbiol. 2017;201:154-61.

14. Zhou B. Classical swine fever in China-An update minireview. Front Vet Sci. 2019;6:187

15. Wang X, Mu G, Dang R, Yang Z. Up-regulation of IL-10 upon PRRSV vaccination impacts on the immune response against CSFV. Vet Microbiol. 2016;197:68-71.

16. Chen D, Liu X, Xu S, Chen D, Zhou L, Ge X, et al. TNF-a induced by porcine reproductive and respiratory syndrome virus inhibits the replication of classical swine fever virus C-strain. Vet Microbiol. 2019;234:25-33.

17. Hu D, Lv L, Gu J, Chen T, Xiao Y, Liu S. Genetic diversity and positive selection analysis of classical swine fever virus envelope protein gene E2 in East China under C-strain vaccination. Front Microbiol. 2016;7:85.

18. Fatima M, Luo Y, Zhang L, Wang PY, Song H, Fu Y, et al. Genotyping and molecular characterization of classical swine fever virus isolated in China during 2016-2018. Viruses. 2021;13(4):664.

19. Gatto IRH, Sonalio K, de Oliveira LG. Atypical porcine pestivirus (APPV) as a new species of Pestivirus in pig production. Front Vet Sci. 2019;6:35.

20. Hause BM, Collin EA, Peddireddi L, Yuan F, Chen Z, Hesse RA, et al. Discovery of a novel putative atypical porcine pestivirus in pigs in the USA.J Gen Virol. 2015;96(10):2994-8.

21. Pan S, Mou C, Chen Z. An emerging novel virus: atypical porcine pestivirus (APPV). Rev Med Virol. 2019;29(1):e2018.

22. de Groof A, Deijs M, Guelen L, van Grinsven L, van Os-Galdos L, Vogels W, et al. Atypical porcine pestivirus: a possible cause of congenital tremor type A-II in newborn piglets. Viruses. 2016;8(10):271.

23. Bradley R, Done JT, Hebert CN, Overby E, Askaa J, Basse A, et al. Congenital tremor type Al: light and electron microscopical observations on the spinal cords of affected piglets. J Comp Pathol. 1983;93(1):43-59.

24. Cabezón O, Muñoz-González S, Colom-Cadena A, Pérez-Simó M, Rosell R, Lavín S, et al. African swine fever virus infection in classical swine fever subclinically infected wild boars. BMC Vet Res. 2017;13(1):227. 
25. Liu H, Shi K, Sun W, Zhao J, Yin Y, Si H, et al. Development a multiplex RT-PCR assay for simultaneous detection of African swine fever virus, classical swine fever virus and atypical porcine pestivirus. J Virol Methods. 2021;287:114006

26. Agüero M, Fernández J, Romero L, Sánchez Mascaraque C, Arias M, Sánchez-Vizcaíno JM. Highly sensitive PCR assay for routine diagnosis of African swine fever virus in clinical samples. J Clin Microbiol. 2003;41(9):4431-4.

27. Tignon M, Gallardo C, Iscaro C, Hutet E, Van der Stede Y, Kolbasov $D$, et al. Development and inter-laboratory validation study of an improved new real-time PCR assay with internal control for detection and laboratory diagnosis of African swine fever virus. J Virol Methods. 2011;178(1-2):161-70.

28. Hoffmann B, Beer M, Schelp C, Schirrmeier H, Depner K. Validation of a real-time RT-PCR assay for sensitive and specific detection of classical swine fever. J Virol Methods. 2005;130(1-2):36-44.

29. Ophuis RJ, Morrissy CJ, Boyle DB. Detection and quantitative pathogenesis study of classical swine fever virus using a real time RT-PCR assay. J Virol Methods. 2006;131(1):78-85.

30. Chen F, Knutson TP, Braun E, Jiang Y, Rossow S, Marthaler DG. Semi-quantitative duplex RT-PCR reveals the low occurrence of porcine pegivirus and atypical porcine pestivirus in diagnostic samples from the United States. Transbound Emerg Dis. 2019;66(3):1420-5.

31. Grau FR, Schroeder ME, Mulhern EL, Mclntosh MT, Bounpheng MA. Detection of African swine fever, classical swine fever, and footand-mouth disease viruses in swine oral fluids by multiplex reverse transcription real-time polymerase chain reaction. J Vet Diagn Invest. 2015;27(2):140-9.

32. Haines FJ, Hofmann MA, King DP, Drew TW, Crooke HR. Development and validation of a multiplex, real-time RT PCR assay for the simultaneous detection of classical and African swine fever viruses. PLoS One. 2013;8(7):e71019.

33. Ge S, Li J, Fan X, Liu F, Li L, Wang Q, et al. Molecular characterization of African swine fever virus, China, 2018. Emerg Infect Dis. 2018;24(11):2131-3

34. Sun E, Huang L, Zhang X, Zhang J, Shen D, Zhang Z, et al. Genotype I African swine fever viruses emerged in domestic pigs in China and caused chronic infection. Emerg Microbes Infect. 2021;10:1-30.

35. Hawkins SFC, Guest PC. Multiplex analyses using real-time quantitative PCR. Methods Mol Biol. 2017;1546:125-33.

36. Hoffmann B, Beer M, Reid SM, Mertens P, Oura CA, van Rijn PA, et al. A review of RT-PCR technologies used in veterinary virology and disease control: sensitive and specific diagnosis of five livestock diseases notifiable to the world organization for animal health. Vet Microbiol. 2009;139(1-2):1-23.

37. Gallardo C, Sánchez EG, Pérez-Núñez D, Nogal M, de León P, Carrascosa ÁL, et al. African swine fever virus (ASFV) protection mediated by NH/P68 and NH/P68 recombinant live-attenuated viruses. Vaccine. 2018;36(19):2694-704.

38. Sun E, Zhang Z, Wang Z, He X, Zhang X, Wang L, et al. Emergence and prevalence of naturally occurring lower virulent African swine fever viruses in domestic pigs in China in 2020. Sci China Life Sci. 2021;64(5):752-65.

39. Patrick BN, Machuka EM, Githae D, Banswe G, Amimo JO, Ongus JR, et al. Evidence for the presence of African swine fever virus in apparently healthy pigs in south-Kivu Province of the Democratic Republic of Congo. Vet Microbiol. 2020;240:108521.

40. Gallardo C, Nurmoja I, Soler A, Delicado V, Simón A, Martin E, et al. Evolution in Europe of African swine fever genotype II viruses from highly to moderately virulent. Vet Microbiol. 2018;219:70-9.

41. de Villiers EP, Gallardo C, Arias M, da Silva M, Upton C, Martin R, et al. Phylogenomic analysis of 11 complete African swine fever virus genome sequences. Virology. 2010;400(1):128-36.

42. Giammarioli M, Gallardo C, Oggiano A, Iscaro C, Nieto R, Pellegrini C, et al. Genetic characterisation of African swine fever viruses from recent and historical outbreaks in Sardinia (1978-2009). Virus Genes. 2011;42(3):377-87.

43. Njau EP, Domelevo Entfellner JB, Machuka EM, Bochere EN, Cleaveland S, Shirima GM, et al. The first genotype II African swine fever virus isolated in Africa provides insight into the current Eurasian pandemic. Sci Rep. 2021;11(1):13081.
44. Wang F, Zhang H, Hou L, Yang C, Wen Y. Advance of African swine fever virus in recent years. Res Vet Sci. 2021;136:535-9.

45. Bastos AD, Penrith ML, Crucière C, Edrich JL, Hutchings $G$, Roger F, et al. Genotyping field strains of African swine fever virus by partial p72 gene characterisation. Arch Virol. 2003;148(4):693-706.

\section{Publisher's Note}

Springer Nature remains neutral with regard to jurisdictional claims in published maps and institutional affiliations.

Ready to submit your research? Choose BMC and benefit from:

- fast, convenient online submission

- thorough peer review by experienced researchers in your field

- rapid publication on acceptance

- support for research data, including large and complex data types

- gold Open Access which fosters wider collaboration and increased citations

- maximum visibility for your research: over 100M website views per year

At BMC, research is always in progress.

Learn more biomedcentral.com/submissions 